\title{
Anesthesia and surgical trauma: their influence on the guinea pig compound action potential *
}

\author{
M. Christian Brown, D. Ian Smith and Alfred L. Nuttall \\ Kresge Hearing Research Institute, University of Michigan Medical School, Ann Arbor, MI 48109, U.S.A.
}

(Received 23 August 1982; accepted 3 February 1983)

\begin{abstract}
A chronic implant consisting of a fine thermocouple placed on the round window permitted measurement of temperature and of the compound action potential (CAP) of the cochlear nerve in guinea pigs. Thresholds and latencies of the CAP, in response to tone bursts $(2-40 \mathrm{kHz})$, were measured when the animal was awake and unrestrained, and again after several hours of anesthesia. The CAP remained unchanged with a variety of common anesthetics when precise control of round window temperature was maintained. However, when anesthesia was accompanied by several hours of slight cochlear cooling. thresholds were elevated for CAPs evoked by frequencies above $24 \mathrm{kHz}$ and latencies were increased for CAPs evoked by all frequencies tested.

The effects of surgery on CAP threshold and latency were also examined. Guinea pigs were tested while still anesthetized at the conclusion of the implantation procedure, and then again several days later while awake. Thresholds and latencies were unchanged. In two anesthetized guinea pigs already implanted with thermocouples, ventral and post-auricular surgery to expose the middle ear had no effect on the CAP, when low-speed drilling was used to open the auditory bulla. However, when small portions of the bulla were broken away with forceps, the CAP in response to high-frequency tone bursts immediately showed elevated thresholds. This alteration of the CAP was clearly different from that produced by lowered temperature, since the latencies at threshold were significantly decreaced
\end{abstract}

Key words: anesthesia; cochlear temperature; compound action potential; guinea pig: surgery.

\section{Introduction}

Deeply anesthetized animals are commonly used in cochlear electrophysiological research. Many experiments require an anesthetized and immobile preparation because of constraints of stimulus delivery and cochlear potential recording. Some investigators $[19,6]$ have warned that results from anesthetized and possibly surgically traumatized preparations must be interpreted with caution. It is possible to measure bioelectric potentials from the round window of the cochlea and from the eighth nerve using unanesthetized animals. Yet, only a few studies have been made of the effects of anesthesia and surgery on the peripheral auditory potentials $[24,27,6,25]$. In one of these investigations, Cazals et al. [6] showed higher thresholds

* Submitted by M.C. Brown in partial fulfillment of the requirements for the Ph. D. Thesis in the Physiological Acoustics program, University of Michigan. 
for the compound action potential (CAP) in response to sound stimuli above about $20 \mathrm{kHz}$ in anesthetized than in awake guinea pigs. However, the authors could not be certain whether the anesthetic acted directly on the cochlea or indirectly by altering some other physiological system. In addition, surgical intervention was found to produce greater elevations of thresholds, which extended to lower frequencies.

In our recent work recording from inner hair cells of the basal turn of the cochlea $[22,4]$, we routinely recorded CAP thresholds in response to high-frequency tone bursts. It was discovered that a decreased cochlear temperature could produce CAP threshold elevations [2,3]. Also, CAP thresholds could be increased by the noise made when a chip of bone was removed from the auditory bulla with forceps. We undertook this study in an effort to separate the often interconnected variables of anesthesia, temperature and surgical trauma and to examine how they affect the guinea pig CAP.

\section{Methods}

\section{Thermocouple implant procedure}

Round window thermocouples were implanted in albino guinea pigs weighing $300-500 \mathrm{~g}$ by a procedure patterned on that of Aran and Erre [1]. The animals were anesthetized with freshly prepared sodium pentobarbital $(7.5 \mathrm{mg} / \mathrm{kg}$, i.p.), and 15 min later, with Innovar-Vet $(0.2 \mathrm{ml} / \mathrm{kg}$, i.m. $)$. They were warmed by a heating blanket and rectal temperature was measured with a thermistor. Light sources held within $10 \mathrm{~cm}$ of the guinea pig were sometimes used to warm the surgical field. After a post-auricular dissection was performed, a hole $(1.5 \mathrm{~mm}$ diameter) was drilled in the bulla. A thermocouple measuring junction was prepared by stripping the Teflon insulation from the last $2 \mathrm{~mm}$ of chromel and alumel wires $(0.075 \mathrm{~mm}$ diameter), winding the wires together, and soldering them. The measuring junction was twisted with forceps to form a smooth $1 \mathrm{~mm}$ loop. The loop was placed on the round window and the bulla was sealed with dental cement (carboxylate), securing the thermocouple wires to the bulla. Thermocouple wires were led subcutaneously to connectors in a plug mounted on top of the skull with dental cement. A reference wire from a screw in the skull was also led to the plug. The post-auricular incision was closed with wound clips.

\section{Sound stimulation}

Sound stimuli were produced by a 1/2-inch condenser microphone system which was compensated for distortion. The microphone was mounted on the skull plug and coupled to the external auditory meatus through a $10 \mathrm{~cm}$ silastic tube. The tube was glued into the meatus with alphacyanoacrylate cement to form a closed acoustic system [1]. Sound stimuli were tone bursts of $1 \mathrm{~ms}$ rise-fall time with approximately sinusoidal rising and falling envelopes. Tone bursts were of $15 \mathrm{~ms}$ duration and were repeated every $100 \mathrm{~ms}$. Actual sound pressure levels were not measured. 


\section{Recordings}

Thermocouples were led to a meter which displayed temperature (Analog Devices Model 2036). The meter read $0^{\circ} \mathrm{C}$ when a thermocouple was immersed in an ice-water bath and $100^{\circ} \mathrm{C}$ when immersed in boiling water, and it was assumed to be correct for intermediate values. Air temperature was about $23^{\circ} \mathrm{C}$ during the experiments.

Since the implanted thermocouples were not insulated at the tip, it was possible to use one of the wires to record the CAP from the round window. Signals were band-pass filtered between $30 \mathrm{~Hz}$ and $40 \mathrm{kHz}$ and were amplified 100 fold. Thresholds and latencies were measured visually from an oscilloscope. Latency is defined as the time between the point at which the electrical signal giving rise to the tone burst reaches $10 \%$ of its maximal level and the first negative peak $\left(\mathrm{N}_{1}\right)$ of the CAP. To facilitate the 'latency at threshold' measurement, the SPL was increased by an amount $(<3 \mathrm{~dB})$ just sufficient to see the $\mathrm{N}_{1}$ peak. Experiments were conducted in a sound-shielded booth.

\section{Results}

\section{Effects of anesthetics on the CAP with normal round window temperature}

For this experiment, 6 guinea pigs received thermocouple implants and were allowed at least 3 days for recovery. While awake, resting in a cage, the animals had an average round window temperature of $38.5^{\circ} \mathrm{C}$, as measured during daylight or early evening hours. When handled, e.g. when the sound tube was glued into the external acoustic meatus, their round window temperature temporarily climbed

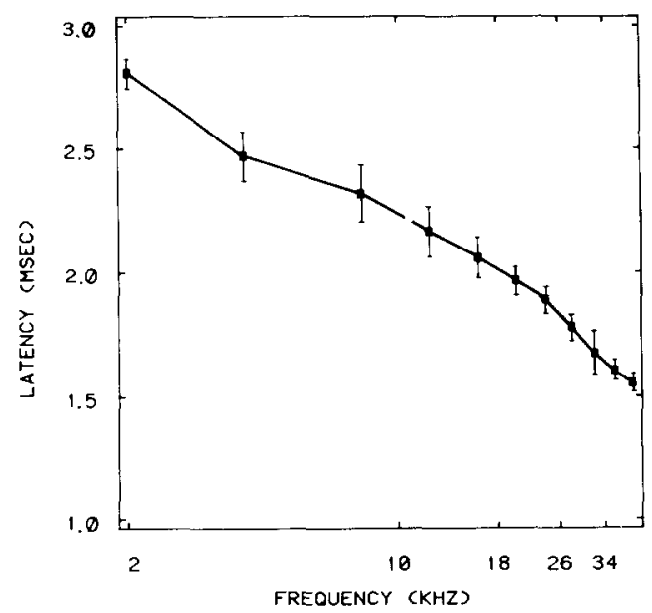

Fig. 1. CAP latencies (at threshold) in response to tone bursts with a $1 \mathrm{~ms}$ rise time. Squares show averages for 6 awake guinea pigs. Vertical bars show standard deviations. Latency is measured from the point at which the electrical signal giving rise to the tone burst reaches $10 \%$ of its maximal level to the first negative peak $\left(\mathrm{N}_{1}\right)$ of the CAP. 
TABLE I

ANESTHETIC DOSAGES

\begin{tabular}{|c|c|c|}
\hline Anesthetic & Dose & $\begin{array}{l}\text { No. of } \\
\text { animals } \\
\text { tested }\end{array}$ \\
\hline $\begin{array}{l}\text { Sodium pentobarbital }{ }^{a} \\
\text { Innovar-Vet }^{b}\end{array}$ & $\begin{array}{l}7.5 \mathrm{mg} / \mathrm{kg} \text { i.p. } \\
0.2 \mathrm{ml} / \mathrm{kg} \text { i.m. }\end{array}$ & 2 \\
\hline $\begin{array}{l}\text { Sodium pentobarbital } \\
\text { Innovar-Vet }\end{array}$ & $\begin{array}{l}15 \mathrm{mg} / \mathrm{kg} \text { i.p. } \\
0.5 \mathrm{ml} / \mathrm{kg} \text { i.m. }\end{array}$ & 1 \\
\hline Sodium pentobarbital & $25 \mathrm{mg} / \mathrm{kg}$ i.p. & 2 \\
\hline Sodium pentobarbital & $50 \mathrm{mg} / \mathrm{kg}$ i.p. & 1 \\
\hline $\begin{array}{l}\text { Levomepromazine } \\
\text { Atropinc } \\
\text { Ketamine }\end{array}$ & $\begin{array}{c}2.5 \mathrm{mg} \text { i.m. } \\
0.1 \mathrm{mg} \text { i.m. } \\
150 \mathrm{mg} / \mathrm{kg} \text { i.p. }\end{array}$ & 2 \\
\hline Urethane & $1500 \mathrm{mg} / \mathrm{kg}$ i.p. & 2 \\
\hline Dial $^{d}$ & $0.8 \mathrm{ml} / \mathrm{kg}$ i.p. & 1 \\
\hline
\end{tabular}

several tenths of a degree and not uncommonly rose above $39^{\circ} \mathrm{C}$. Baseline CAP thresholds and latencies were obtained in the awake condition. Since sound pressures were not measured, most experimental data are plotted as threshold elevations and latency increases relative to these awake values. Absolute latencies were measured, however, and average values are shown for these 6 awake guinea pigs in Fig. 1.

Animals were anesthetized with the agents and dosages as listed in Table I. In these anesthetized animals, rectal temperatures measured just after anesthesia were about $38.5^{\circ} \mathrm{C}$. With rectal temperature maintained at this value by a heating blanket, round window temperature was also held at $38.5^{\circ} \mathrm{C}$. CAP thresholds and latencies were again determined after $2-3 \mathrm{~h}$ of anesthesia. For the experiment in which Dial with urethane was the anesthetic, a respirator was used to ventilate the guinea pig.

Fig. 2 shows the effects of sodium pentobarbital $(25 \mathrm{mg} / \mathrm{kg})$ on CAP thresholds and latencies when round window temperature was precisely controlled at $38.5^{\circ} \mathrm{C}$ (squares, solid lines). The CAP threshold elevations and latency increases which occurred when anesthesia was accompanied by slight cochlear cooling (circles, dashed lines) will be more fully explained in the following section. Data points are the values obtained $2 \mathrm{~h}$ after the anesthetic was administered, plotted relative to the values obtained when the animal was awake. In unanesthetized animals, we consider our threshold measurements accurate to within $\pm 5 \mathrm{~dB}$ and latency measurements 


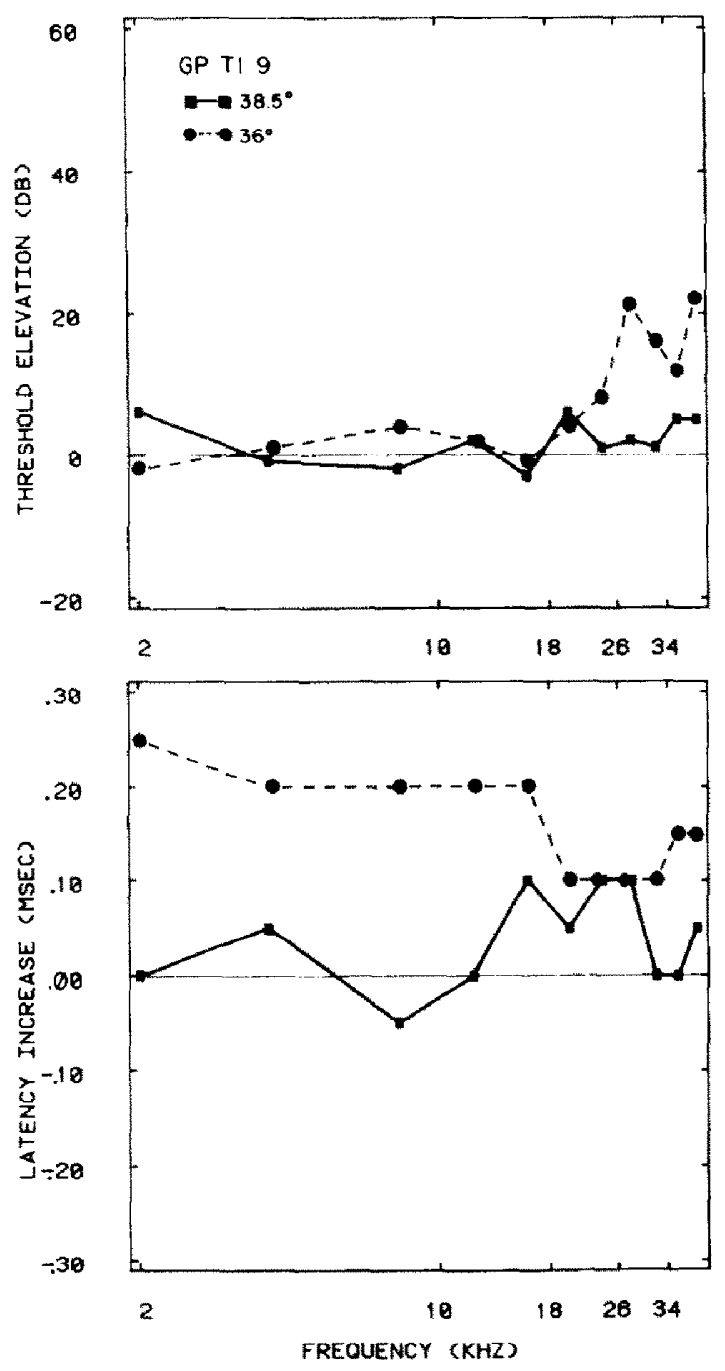

Fig. 2. CAP threshold elevations and latency increases relative to the awake condition. Values were taken $2 \mathrm{~h}$ after the guinea pig was anesthetized with sodium pentobarbital $(25 \mathrm{mg} / \mathrm{kg})$. In one experiment, round window and rectal temperatures were maintained at $38.5^{\circ} \mathrm{C}(\mathbf{m}-\mathbf{m})$ and in another experiment using the same guinea pig, were allowed to decrease to $36^{\circ} \mathrm{C}(\bullet-\ldots)$.

accurate to within $\pm 0.1 \mathrm{~ms}$. In anesthetized animals, the recording was less noisy and the measurements were somewhat more accurate. Negligible changes in the CAP were observed in response to tone bursts ranging in frequency from 2 to $40 \mathrm{kHz}$. Results for Innovar-Vet $(0.2 \mathrm{ml} / \mathrm{kg}$ ) are shown in Fig. 3 (squares connected by solid lines). CAP thresholds and latencies held constant for each anesthetic listed in Table I. The largest threshold shift observed with normal round window temperature was a $16 \mathrm{~dB}$ lowering of threshold in response to an $8 \mathrm{kHz}$ tone burst, and the 

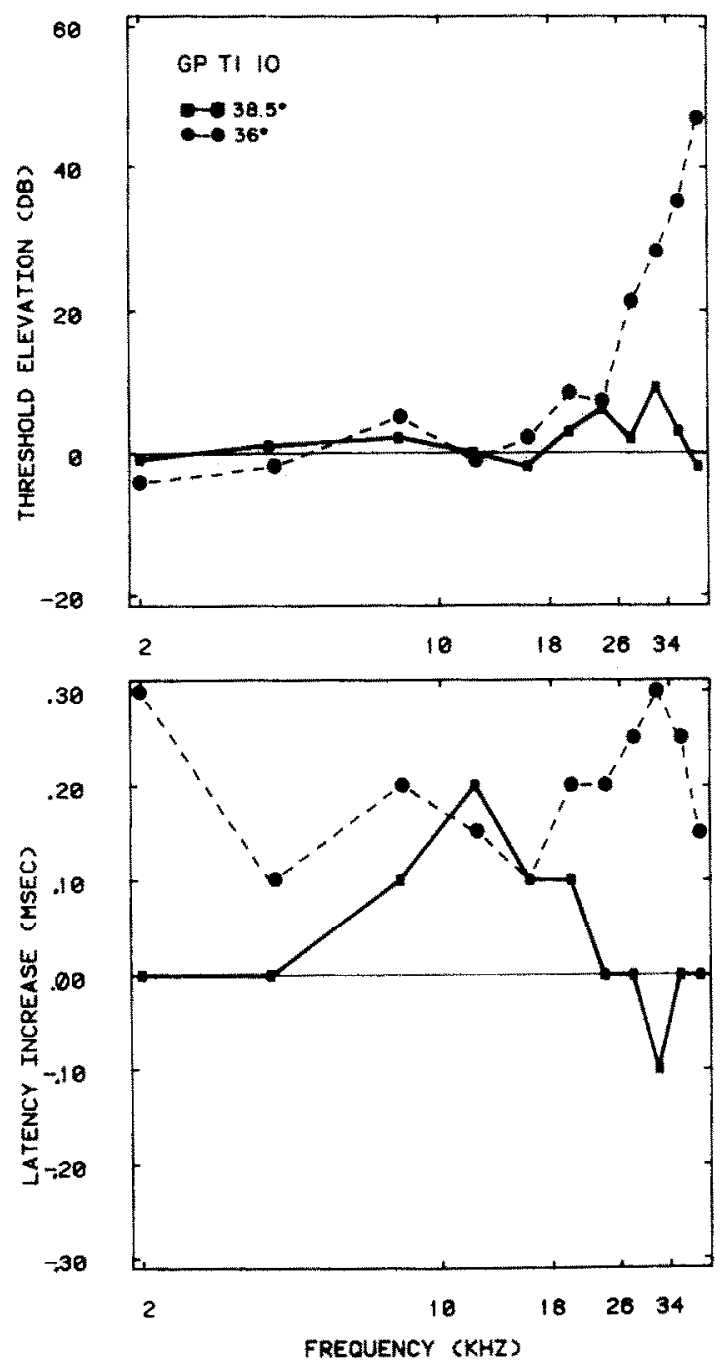

Fig. 3. CAP threshold elevations and latency increases as in Fig. 2. Innovar-Vet anesthetic $(0.2 \mathrm{ml} / \mathrm{kg})$ with round window and rectal temperatures held at $38.5^{\circ} \mathrm{C}(\square-\infty)$ and at $36^{\circ} \mathrm{C}(-\ldots)$

largest threshold elevation was $9 \mathrm{~dB}$ in response to a $16 \mathrm{kHz}$ tone burst, both in the guinea pig anesthetized with Innovar-Vet $(0.5 \mathrm{ml} / \mathrm{kg}$ ) (not illustrated). Fig. 4 shows average threshold and latency measurements for all anesthetic tests pooled together. Thresholds and latency shifts were small and showed no general trends with frequency.

The animals anesthetized with urethane or with Dial were killed at the conclusion of the experiments. In all other cases, however, the guinea pigs recovered successfully from anesthesia. 


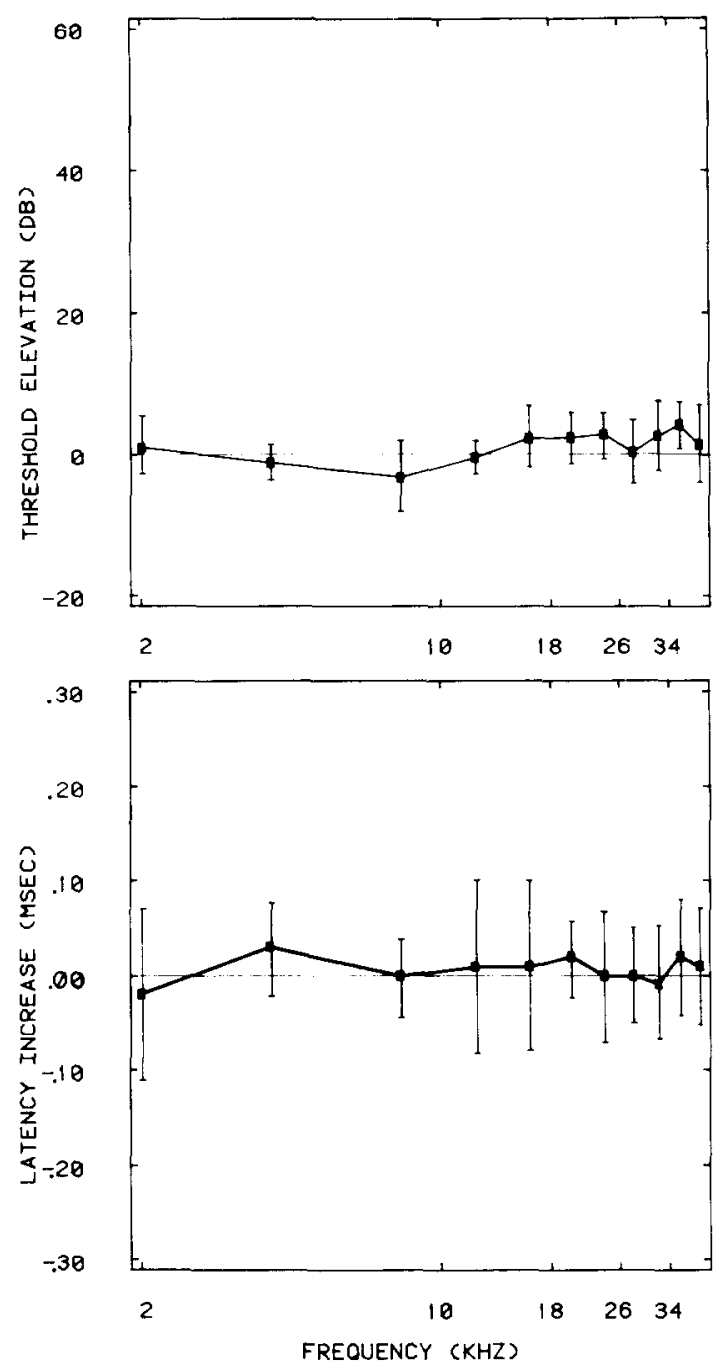

Fig. 4. Average CAP threshold elevations and latency increases for all anesthetics tested (Table I). Round window and rectal temperatures were maintained at $38.5^{\circ} \mathrm{C}$.

\section{Effects of round window cooling}

In four guinea pigs, CAP thresholds and latencies were measured when anesthesia was accompanied by slight cooling. Whole-body cooling was achieved passively by supplying less heat from the heating blanket. Typical results are shown in Figs. 2 and 3 (circles connected by dashed lines), measured $2 \mathrm{~h}$ after the anesthetics were administered. Rectal and round window temperatures were held at $36^{\circ} \mathrm{C}$. Thresholds. relative to the awake condition, were elevated in response to tone bursts with frequencies greater than $24 \mathrm{kHz}$. Latencies increased for most frequencies tested. 
Similar results were observed when two other animals were cooled to about $36^{\circ} \mathrm{C}$ after ketamine anesthetic was administered. Cooling to $36^{\circ} \mathrm{C}$ always caused threshold elevations for CAPs evoked by high-frequency tone bursts but thresholds were normal in response to tone bursts with frequencies below $16 \mathrm{kHz}$. Latencies increased more uniformly with frequency. The same anesthetics administered to the same guinea pigs did not cause threshold or latency changes when anesthesia was not accompanied by cooling.

\section{Effects of surgery}

In 3 guinea pigs, CAPs were measured just after implantation of the round window thermocouple. The bulla had been sealed and the incision in the skin was closed but the guinea pig was still anesthetized. These animals had been warmed during surgery by illuminators and round window temperature was held at about $38.5^{\circ} \mathrm{C}$ after the thermocouple was in place. CAPs were again measured at least several days later (awake condition). Thresholds measured post-surgery were usually within $10 \mathrm{~dB}$ of those in the awake condition, and no clear pattern of threshold or latency changes was observed for different frequencies. Fig. 5 shows average threshold elevations and latency increases for these three guinea pigs just after conclusion of the implantation surgery, plotted relative to the awake values.

In three other guinea pigs, round window and rectal temperatures were allowed to decrease several degrees below normal during implantation surgery. For this type of surgical exposure, round window temperature was about $1^{\circ} \mathrm{C}$ below rectal temperature when no light sources illuminated the surgical area. Just after surgery, each of these guinea pigs showed a threshold elevation in response to high-frequency tone bursts, relative to the values obtained in the awake condition. Two of these guinea pigs were warmed for $3 \mathrm{~h}$ after the conclusion of the surgery, restoring round window and rectal temperatures to $38.5^{\circ} \mathrm{C}$. After $3 \mathrm{~h}$ at normal temperature, most thresholds and latencies were similar to the values obtained several days later when the animal was awake.

We also examined whether more invasive surgery, including a ventral approach to the bulla and middle ear, could affect the CAP. Two guinea pigs were used from the anesthetic study reported above. Baseline CAP thresholds and latencies had been obtained while the animal was awake and then the guinea pig was anesthetized (urethane anesthetic in one case, Dial anesthetic in the other, Table I). The guinea pig anesthetized with Dial was artificially ventilated. After several hours with round window temperature maintained at $38.5^{\circ} \mathrm{C}, \mathrm{CAP}$ thresholds and latencies were unchanged relative to the awake condition. Artificial ventilation was then also begun for the urethane-anesthetized guinea pig. Round window temperature during the following surgery was kept at $38.5^{\circ} \mathrm{C}$ by the use of light sources illuminating the surgical field. The sound tube was unglued, the pinna removed, and the tube re-glued to the external meatus. The bulla was approached post-auricularly until the thermocouple wires were visible. Then, a ventral dissection was performed, including ligation of the facial veins, removal of the posterior tip of the lower mandible and masseter muscle, and removal of the digastric muscle. The implanted thermocouple was removed and the post-auricular opening in the bulla was enlarged, using quiet, 

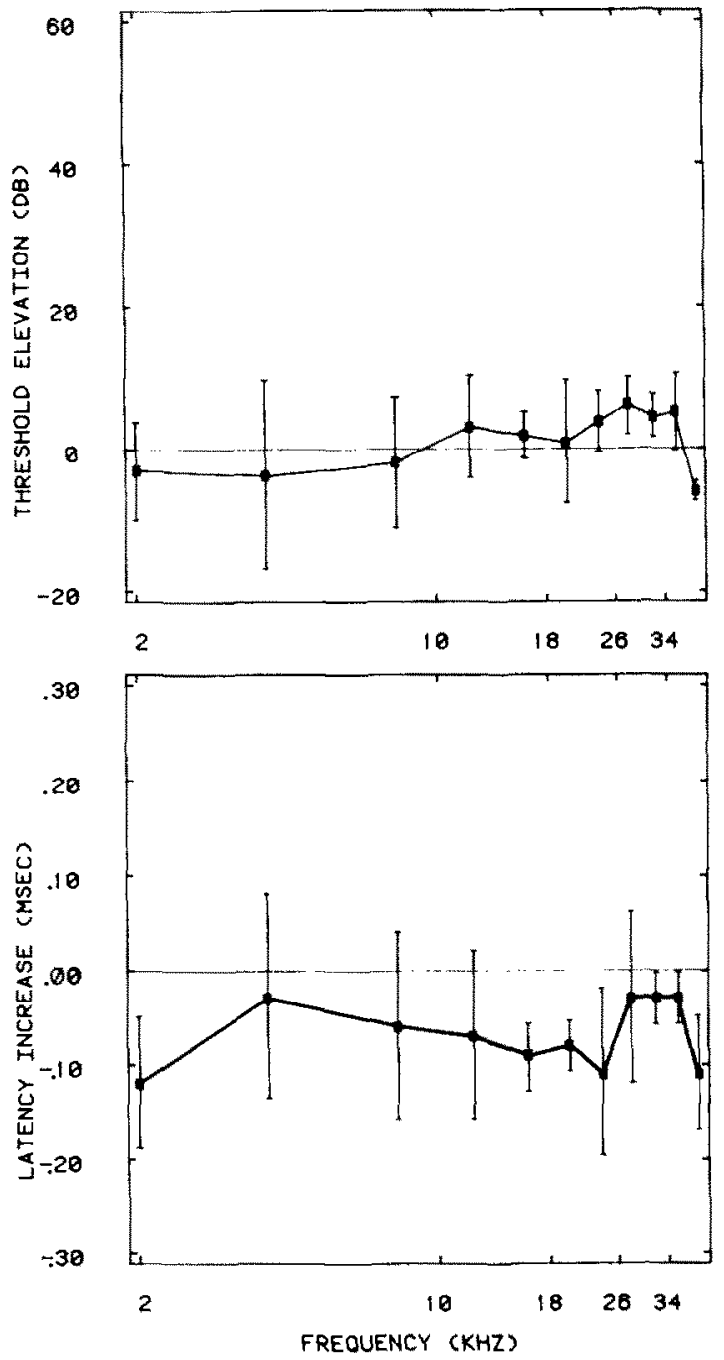

Fig. 5. Average CAP threshold elevations and latency increases for three guinea pigs just after implantation surgery, relative to the awake condition recorded at least several days later. Round window temperature was held at $38.5^{\circ} \mathrm{C}$ during surgery.

low-speed drilling with a dental drill. A new thermocouple was placed on the round window. A ventral opening (about $4 \mathrm{~mm}$ diameter) was also made in the bulla by drilling. A bridge of bone about $4 \mathrm{~mm}$ in width separated the post-auricular and ventral openings in the bulla, and the styloid process was left in place. This exposure of the middle ear is similar to that used for recordings from inner hair cells [26]. Opening the bulla would not be expected to significantly alter the SPL delivered to the tympanic membrane at the high frequencies tested in this experiment [28]. CAP 

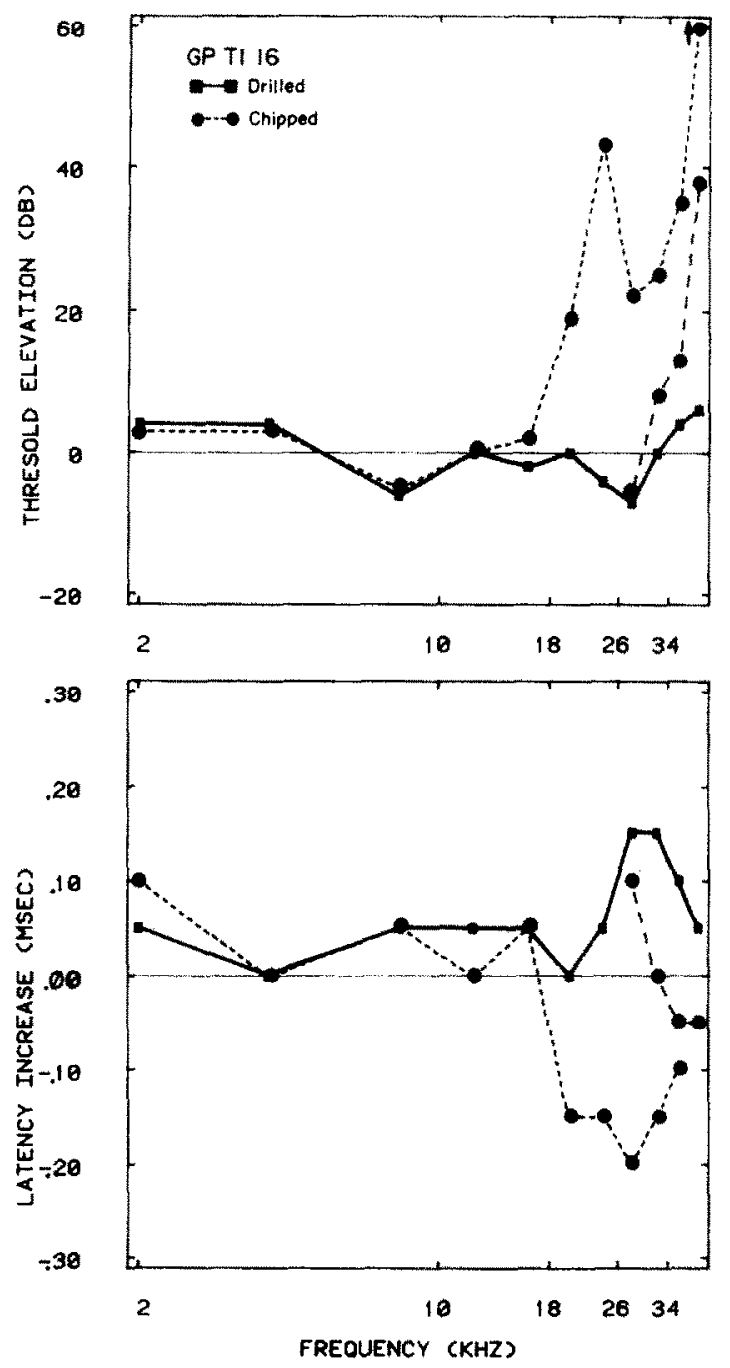

Fig. 6. CAP threshold elevations and latency increases after post-auricular and ventral surgery, using drilling to open the auditory bulla (-C) CAP changes after a few $1 \mathrm{~mm}$ chips of bulla were removed with Lempert malleus snippers (-. _ - ) and after several more chips were removed (๑....-.). This guinea pig was anesthetized with urethane and round window temperature was maintained at $38.5^{\circ} \mathrm{C}$.

thresholds and latencies were measured after this surgery and data from one animal are plotted in Fig. 6 (solid lines). In both animals, there were only negligible changes in the CAP from this surgery.

In addition to drilling, there are other methods of opening the auditory bulla. In one method, the tip of a scalpel is rotated to drill a small hole in the bulla. The 
opening is then enlarged by removing small segments of the bulla with forceps or Lempert malleus snippers. The fracturing of these bone segments often generates a slight cracking noise. We have observed that this procedure can elevate thresholds for the CAP in response to high frequency $(>16 \mathrm{kHz})$ tone bursts. To illustrate this point, the same two guinea pigs used in the surgery tests just mentioned were used to study the effects of removal of small segments of bone from the ventral aspect of the bulla. Fig. 6 (dashed lines) shows the threshold and latency changes observed after the ventral opening in the bulla was enlarged anteriorly about $2 \mathrm{~mm}$, using Lempert malleus snippers. Care was taken to avoid damaging the tympanic membrane. Several segments of bulla were removed and slight cracking noises were heard by the investigator, but no visible bleeding or damage to the ossicular chain or tympanic membrane occurred. The dotted lines in Fig. 6 show CAP changes which occurred after several more segments of the bulla were removed, enlarging the ventral opening in the bulla further anteriorly about $1 \mathrm{~mm}$. These procedures caused elevations of CAP thresholds in response to tone bursts above $16 \mathrm{kHz}$. Threshold elevations increased with increasing frequency, and for the highest frequency tested $(40 \mathrm{kHz})$, the CAP threshold was beyond the range of our sound system. Latencies at threshold were unchanged for responses to low frequencies but were significantly decreased for the responses to high frequencies which had elevated thresholds.

Several other observations on this type of injury have been made, using acute preparations. Small segments of bone can sometimes be removed silently from the bulla, without changing the CAP. However, when the usual cracking noise accompanies bone removal, threshold elevations occur. The CAP changes occur immediately after the noise and there is no recovery of the CAP within several hours after the injury. CAP changes can also occur with removal of the tip of the styloid process, using malleus snippers, when the ventral bulla is intact. In several attempts, we have not been able to induce CAP changes with cracking noises made by removal of hone segments from a separate temporal bone, held within several centimeters of an opened guinea pig bulla.

\section{Discussion}

The principal finding of this report was the lack of CAP threshold or latency (at threshold) changes with a variety of commonly used anesthetics. This is in agreement with earlier observations on the effects of sodium pentobarbital anesthesia [24,27] on activity of single units in the eighth nerve of cats. Rupert et al. [24] recorded from units with characteristic frequencies up to $48 \mathrm{kHz}$ and Simmons and Linehan [27] recorded from one unit with a characteristic frequency equal to $3.2 \mathrm{kHz}$.

However, in a CAP study, Cazals et al. [6] showed threshold elevations for responses to filtered clicks with frequencies higher than about $20 \mathrm{kHz}$ in anesthetized, intact guinea pigs, relative to the awake condition. Threshold elevations were greater for higher frequencies and were up to $30 \mathrm{~dB}$ for the highest frequency tested $(40 \mathrm{kHz})$. Anesthesia accompanied by surgery to implant the round window electrode caused larger CAP threshold elevations at high frequencies. In addition, CAP 
thresholds in response to tone bursts with frequencies as low as $12 \mathrm{kHz}$ were elevated. Latencies increased for CAPs evoked by tone bursts of $2-40 \mathrm{kHz}$, but not for frequencies below $2 \mathrm{kHz}$. The latency increases of several tenths of a millisecond were approximately uniform across the $2-40 \mathrm{kHz}$ frequency range, unlike the threshold changes. In their study, cochlear temperature was not measured and rectal temperature was sometimes controlled at $36^{\circ} \mathrm{C}$. In a control experiment in which rectal temperature was varied from 28 to $38^{\circ} \mathrm{C}$. latencies were lengthened at $28^{\circ} \mathrm{C}$ and became similar to the awake condition at $38^{\circ} \mathrm{C}$, whereas the high-frequency threshold shift seemed independent of temperature. The investigators speculated that a direct effect of anesthesia on the cochlea, or an indirect action of anesthesia on some other physiological system, might account for the changes seen.

We have shown in this study and in others $[2,3]$ that a decrease in round window temperature from the normal value of 38.5 to $36^{\circ} \mathrm{C}$ produced threshold shifts in response to tone bursts with frequencies higher than about $20 \mathrm{kHz}$. These threshold shifts were greater for higher frequencies and can sometimes be as great as $40 \mathrm{~dB}$ at $40 \mathrm{kHz}$. Latencies increased approximately uniformly over the frequency range tested $(2-40 \mathrm{kHz})$. In other studies [2,3], cooling acute preparations to lower temperatures caused larger threshold shifts which extended to lower frequencies. Latencies increased further, again more uniformly with frequency. For 4-h cooling periods, latency changes occurred more rapidly and recovered more quickly than threshold shifts. It sometimes took $2 \mathrm{~h}$ after rewarming for thresholds to recover completely. These observations are in agreement with earlier studies of the influence of temperature on the CAP evoked by clicks $[18,12,5,7,13,9]$ and by tone bursts [15]. These earlier studies have shown lowered temperatures produce either elevated CAP thresholds or a decrease in suprathreshold CAP amplitude which is accompanied by an increase in CAP latency.

From the similarity of our data for round window temperature of $36^{\circ} \mathrm{C}$ with the effects shown by Cazals et al. [6], we conclude that the CAP changes revealed in their study were caused by a lowered cochlear temperature, an indirect action of anesthetic. We explain the larger effects of surgery shown in their study by the inevitable decrease in cochlear temperature in the surgically exposed cochlea, shown in this study and others [28,21,3]. We also base this conclusion on the minimal changes in CAP after several types of surgery used in this study. The round window implantation procedure used by Cazals et al. [6] required the drilling of 2 holes of 0.3 $\mathrm{mm}$ and $1.0 \mathrm{~mm}$ diameter in the wall of the auditory bulla; hence the type of surgical trauma observed in the present study was unlikely. In addition, Cazals et al. [6] observed increased CAP latencies over a wide frequency range, yet the surgical trauma shown in the present study produced decreased latencies, for high-frequency responses.

The use of forceps to remove segments of bone from the bulla in guinea pigs should be discouraged. Low-speed drilling with a dental drill is a method to make openings into the bulla with acceptable preservation of the response to high-frequency tone bursts. The CAP changes observed in this study after segments of the bulla were removed with forceps are similar to changes which might be expected after exposure to some types of acoustic overstimulation. Certain types of impulse noise 
can produce anatomical changes restricted to the extreme basal turn in monkeys [17] and in chinchillas $[14,20]$, although due to the large variability in the results, it is difficult to make a general statement about the effects of exposure to impulse noise. Portmann et al. [23] measured CAPs in response to filtered clicks $(1 \ldots 8 \mathrm{kHz})$ after white noise exposures in guinea pigs. Thresholds were elevated and latencies (at threshold) decreased, in response to the high-frequency filtered clicks. Responses to the lower frequencies were not modified. It seems reasonable to assume that the injury produced in the present study is noise-induced and possibly caused by bone-conducted sound.

Finally. we note that studies have shown a discrepancy at high frequencies between acute recordings of eighth nerve electrophysiological thresholds and behavioral thresholds $[10,11,16,8,6]$. This discrepancy may result in part from the difference in cochlear temperature between the acute, anesthetized preparation and the awake. behaving animal. However, the noise-induced surgical trauma revealed in this report may also be a contributing factor.

\section{Acknowledgements}

The authors wish to thank Dr. Joseph Hawkins, Jr. for his encouragement of this study, and M. Yves Cazals for his valuable suggestions. They also thank Mr. Robert Masta for technical assistance. This research was supported by research grants NS-15107, NS-11731 and NS-05785, and training grant NS-07106.

\section{References}

1 Aran, J.-M. and Erre, J.-P. (1979): Long-term recording of cochleo-neural potentials in the guinea pig. In: Auditory Investigation: The Scientific and Technological Basis, pp. 233-261. Editor: H.A. Beagley. Oxford University Press, Oxford.

2 Brown, M.C., Smith, D.I. and Nuttall. A.L. (1982): High frequency threshold elevation of the compound action potential caused by slight cochlear cooling. Abstract presented at the Association for Research in Otolaryngology 5th Midwinter Research Meeting.

3 Brown, M.C., Smith, D.I. and Nuttall, A.L. (1983): The temperature dependency of neural and hair cell responses evoked by high frequencies. J. Acoust. Soc. Am. (in press).

4 Brown. M.C., Nuttall, A.L., Masta, R.I. and Lawrence, M. (1983): Cochlear inner hair cells: Effects of transient asphyxia on intracellular potentials. Hearing Res. 9, 131-144.

5 Butler, R.A., Konishi, I. and Fernández, C. (1960): I emperature coefficients of cochlear potentials. Am. J. Physiol. 199, 688-692.

6 Cazals, Y., Aran, J.-M. and Hawkins, J.E. Jr. (1980): Threshold elevation at high frequencies of the auditory nerve action potential in acute versus chronic recordings in guinea pigs. Ilearing Res. 2. 95-109.

7 Coats, A.C. (1965): Temperature effects on the peripheral auditory apparatus. Science 150, $1481 \ldots 1483$.

8 Dallos, P., Harris, D., Ozdamar, O. and Ryan, A. (1978): Behavioral, compound action potential, and single unit thresholds: Relationship in normal and abnormal ears. J. Acoust. Soc. Am. 64, $151-157$.

9 Eggermont, J.J. (1974): The temperature dependency of cochlear adaptation and masking in the guinea pig. Audiology 13, 147-161.

10 Evans, E.F. (1972): The frequency response and other properties of single fibres in the guinea pig cochlear nerve. J. Physiol. 226, 263-287. 
11 Evans, E.F. (1975): Cochlear nerve and cochlear nucleus. In: Handbook of Sensory Physiology. Vol. 5, Pt. 2, pp. 1-108. Editors: W.D. Keidel and W.D. Neff. Springer-Verlag, Berlin.

12 Fernandez, C., Singh, H. and Perlman, H. (1958): Effect of short-term hypothermia on cochlear responses. Acta Otolaryngol. 49, 189-205.

13 Gannon, R.P., Laszlo, C.A. and Moscovitch, D.H. (1966): The effect of physostigmine on the latency of the cochlear potentials. Acta Otolaryngol. 61, 536-546.

14 Hamernik, R.P., Henderson, D.. Crossley, J.J. and Salvi, R.J. (1974): Interaction of continuous and impulse noise: audiometric and histological effects. J. Acoust. Soc. Am. 55, 117-121.

15 Harrison, J.B. (1965): Temperature effects on responses in the auditory system of the little brown bat Myotis l. lucifugus. Physiol. Zool. 38. 34-48.

16 Johnstone, J.R. (1977): Properties of ganglion cells from the extreme basal region of guinea pig cochlea. In: Psychophysics and Physiology of Hearing, pp. 89-98. Editors: E.F. Evans and J.P. Wilson. Academic Press, London.

17 Jordan, V.M., Pinheiro, M.L., Chila, K. and Jimenez, A. (1973): Cochlear pathology in monkeys exposed to impulse noise. Acta Otolaryngol. S312, 16-30.

18 Kahana, L., Rosenblith, W.A. and Galambos, R. (1950): Effect of temperature change on roundwindow response in the hamster. An. J. Physiol. 163, 213-223.

19 Lawrence, M. (1976): Electrophysiology of the inner ear. In: Handbook of Auditory and Vestibular Research Methods, pp. 181-207. Editors: C.A. Smith and J.A. Vernon. C.C. Thomas, Springfield, Ill.

20 Luz, G.A. and Lipscomb, D.M. (1973): Susceptibility to damage from impulse noise: chinchilla versus man or monkey. J. Acoust. Soc. Am. 54. 1750-1754.

21 Nuttall, A.L. and La Rouere, M.J. (1980): Depression of the guinea pig cochlear temperature caused by anesthesia and ventral-approach ear surgery. J. Acoust. Soc. Am. 68, 489-493.

22 Nuttall, A.L., Brown, M.C., Masta, R.I. and Lawrence, M. (1981): Inner hair cell responses to the velocity of basilar membrane motion in the guinea pig. Brain Res. 211, 171-174.

23 Portmann, M., Aran, J.-M. and Coste, Ch. (1973): Vérification expérimentale sur l'animale de quelques aspects électro-cochléographiques de la pathologie humaine. Acta Otolaryngol. 75, 132-142.

24 Rupert, A., Moushegian, G, and Galambos. R. (1963): Unit responses to sound from auditory nerve of the cat. J. Neurophysiol. 26, 449-465.

25 Samara, M. and Tonndorf, J. (1981): Effect of anesthesia on maximal cochlear microphonics. Hearing Res. 5, 337-342.

26 Sellick, P.M. and Russell, I.J. (1979): Intracellular studies of the receptor potentials of inner hair cells of the guinea pig cochlea: techniques. In. Auditory Investigation: The Scientific and Tecluologival Basis, pp. 368-381. Editor: H.A. Beagley. Oxford University Press, Oxford.

27 Simmons, F.B. and Linehan, J.A. (1968): Observations on a single auditory nerve fibre over a six week period. J. Neurophysiol. 31, 799 805 .

28 Vernon, J. and Meikle, M. (1974): Electrophysiology of the cochlea. In: Bioelectric Recording Techniques, Part C, pp. 3-61. Editors: R.F. Thompson and M.M. Patterson. Academic Press, New York. 